(C) 2022, The Authors. Published by Elsevier Inc. and Fass Inc. on behalf of the American Dairy Science Association ${ }^{\circledR}$. This is an open access article under the CC BY license (http://creativecommons.org/licenses/by/4.0/).

\title{
Suitability of milk lactate dehydrogenase and serum albumin for pathogen- specific mastitis detection in automatic milking systems
}

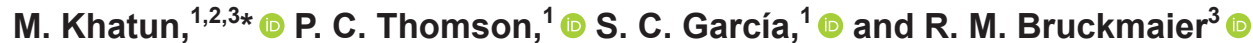 \\ ${ }^{1}$ School of Life and Environmental Sciences and Sydney Institute of Agriculture, The University of Sydney, Camden 2570, New South Wales, \\ Australia \\ ${ }^{2}$ Bangladesh Agricultural University, Mymensingh, Bangladesh, 2202 \\ ${ }^{3}$ Veterinary Physiology, University of Bern, Bremgartenstrasse 109a, 3012 Bern, Switzerland
}

\section{ABSTRACT}

In response to intramammary infection (IMI), bloodderived leukocytes are transferred into milk, which can be measured as an increase of somatic cell count (SCC). Additionally, pathogen-dependent IgG increases in milk following infection. The IgG transfer into milk is associated with the opening of the blood-milk barrier, which is much more pronounced during gram-negative than gram-positive IMI. Thus, milk IgG concentration may help to predict the pathogen type causing IMI. Likewise, lactate dehydrogenase (LDH) and serum albumin (SA) cross the blood-milk barrier with IgG if its integrity is reduced. Because exact IgG analysis is complicated and difficult to automate, LDH activity and SA concentration aid as markers to predict the IgG transfer into milk in automatic milking systems (AMS). This study was conducted to test the hypothesis that $\mathrm{LDH}$ and SA in milk correlate with the IgG transfer, and in combination with SCC these factors allow the differentiation between gram-positive and gram-negative IMI or even more precisely the infection-causing pathogen. Further, the expression of these parameters in foremilk before (BME) and after (AME) milk ejection was tested. In the AMS, quarter milk samples (n = 686) from 48 Holstein-Friesian cows were collected manually BME and AME, followed by an aseptic sample for bacteriological culture. Mixed models were used to (1) predict the concentration of IgG transmitted from blood into milk based on LDH and SA; (2) use principal component analysis to evaluate joint patterns of SCC (cells $/ \mathrm{mL}), \operatorname{IgG}(\mathrm{mg} / \mathrm{mL}), \mathrm{LDH}(\mathrm{U} / \mathrm{L})$, and $\mathrm{SA}(\mathrm{mg} / \mathrm{mL})$ and use the principal component scores to compare gram-positive, gram-negative, and control IMI types and BME versus AME samples; and (3) predict gram-positive and gram-negative IMI by inclusion

\footnotetext{
Received March 17, 2021.

Accepted November 3, 2021.

*Corresponding author: momena.khatun@vetsuisse.unibe.ch or monarahman24@bau.edu.bd
}

of combined SCC-LDH and SCC-SA as predictors in the model. Overall, the SA and LDH had similar ability to predict $\mathrm{IgG}$ transmission from blood into milk. Comparing the areas under the curve (AUC) of the receiver operator characteristic curves, the SCC-LDH versus SCC-SA had lower gram-positive $(\mathrm{AUC}=0.984$ vs. 0.986 ) but similar gram-negative (AUC $=0.995$ vs. 0.998) IMI prediction ability. The SCC, IgG, LDH, and SA were greater in gram-negative than in gram-positive IMI (BME and AME) in early lactation. All measured factors had higher values in milk samples taken BME than AME. In conclusion, LDH and SA could be used as replacement markers to indicate the presence of IgG transfer from blood into milk; in combination with SCC, both SA and LDH are suitable for differentiating IMI type, and BME is better for mastitis detection in AMS.

Key words: mastitis, lactate dehydrogenase, IgG, serum albumin, milk ejection

\section{INTRODUCTION}

Mastitis in dairy cows is an inflammation of the mammary gland that affects animal welfare and has a huge economic impact on the dairy industry worldwide (Halasa et al., 2007; Huijps et al., 2008). Early detection of mastitis including the pathogen causing the disease is the basis for a rapid and efficient treatment decision for the respective mastitis type to minimize the use of antibiotics, to increase animal health and welfare, and to improve the economic return (Milner et al., 1997; Lehmann et al., 2015).

In the immunopathogenesis of IMI during mastitis, the causal pathogens (mostly gram-positive or gramnegative bacteria, or both) induce a response of the innate immune system, but depending on the pathogen type, also of the acquired or specific immune system in the host (Pyörälä, 2003; Schmitz et al., 2004; Wellnitz et al., 2011). The innate immune response is mainly based on the cellular components consisting of circulatory leukocytes, mainly PMN, which migrate from 
blood into the mammary tissue and milk (Wellnitz and Bruckmaier, 2012). This paracellular invasion of PMN is driven by chemoattractants mainly produced by macrophages in the milk as well as mammary epithelial cells that are in contact with bacteria and their pathogen-associated molecular patterns (Burton and Erskine, 2003; Wagner et al., 2009; Bruckmaier and Wellnitz, 2017). To support the innate immune response against the invading mastitis pathogens, there is an elicitation of acquired immune response and transfer of IgG from blood into milk (Burton and Erskine, 2003). It has been shown that the transferred IgG reflects the whole spectrum of antibodies that are present in blood (i.e., not only those directed against the invaded pathogen; Burton and Erskine, 2003; Lehmann et al., 2013; Wellnitz et al., 2013). It has been shown that the loss of blood-milk barrier integrity enhances the IgG transfer into milk, which is much stronger in response to pathogen-associated molecular patterns from gramnegative than gram-positive bacteria (Wellnitz et al., 2013). If specific IgG against the respective pathogen are present because of a previous infection or vaccination, these are considered to opsonize the pathogen and thus facilitate the elimination of the pathogen by the PMN (Burton and Erskine, 2003). Because of the differential transfer of $\operatorname{IgG}$ depending on the invaded pathogen, the increase of $\operatorname{IgG}$ in milk is also considered as a potential marker for pathogen-specific IMI detection if combined with SCC. However, the exact determination of $\operatorname{IgG}$ concentration in milk is complex and is therefore not suitable for automated and fast cow-side analyses in both conventional and automatic milking systems (AMS). Earlier studies indicate that other blood constituents such as lactate dehydrogenase (LDH) and serum albumin (SA) are transferred from blood into milk concomitantly with IgG; these constituents can be more easily analyzed and may serve as markers for the IgG transfer (Lehmann et al., 2013; Wall et al., 2015). Hence, the suitability of LDH and SA to indicate IgG transfer via the blood-milk barrier needs to be studied.

An additional issue is the use of the ideal milk sample that allows the most sensitive detection of mastitis based on SCC, IgG, and related potential markers. All current strategies of mastitis detection in AMS are based on measuring various parameters in foremilk samples obtained after milk ejection (AME) whereas foremilk before milk ejection (BME) cannot be separated. This is due to immediately starting the teat-cleaning process that induces oxytocin release and milk ejection before foremilk is removed (Mačuhová et al., 2003; Dzidic et al., 2004). In our previous study, we have found that milk ejection decreases the power of mastitis detection by LDH (Khatun et al., 2019). Hence, the influence of milk ejection on SCC, IgG, and SA and the combination of these parameters for pathogen-specific IMI detection have not been tested before. Therefore, the objectives of the present study were to investigate (1) if $\mathrm{LDH}$ and SA could be used as alternative markers for IgG in automated mastitis detection and the benefit of the combined use of LDH or SA with SCC to differentiate gram-positive and gram-negative IMI; (2) the differences in in vivo gram-positive and gram-negative IMI for the SCC, IgG, LDH, and SA responses; and (3) the influences of milk ejection on SCC, IgG, LDH, and SA to identify the suitability of foremilk either BME or AME for more efficient automatic mastitis detection in AMS.

\section{MATERIALS AND METHODS}

All procedures involving animals were approved by the Animal Ethics Committee of the University of Sydney. The experiment was conducted at the University of Sydney 'Corstorphine' pasture-based dairy farm located in Camden, NSW, Australia, with 85 ha of effective grazing land. The pasture land is mostly covered with annual ryegrass (Lolium multiflorum) oversown on kikuyu (Pennisetum clandestinum). A partial mixed ration containing primarily brewer's grain, orange pulp, and pasture silage (lucerne hay, oaten hay) and $\sim 7 \mathrm{~kg}$ of $\mathrm{DM} /$ cow grain-based commercial pelleted concentrate $(18 \%$ protein) were provided as a supplement. The calving system was year-round and an automatic rotary system with a 24-unit platform and 5 robotic arms (DeLaval Automatic Milking Rotary) was used for milking the cows.

\section{Milk Sample Collection from Cows}

The selection criteria to collect milk samples from the cows used in this experiment are described in Khatun et al. (2019). In brief, 48 Holstein-Friesian cows were selected for milk sampling based on their having a relatively high electrical conductivity $(\mathbf{E C} ; \geq 7.5$ $\mathrm{mS} / \mathrm{cm}$, at milking temperature, $38^{\circ} \mathrm{C}$ ) in any of the 4 quarters. They had an average of $4.34 \pm 1.99$ (mean \pm SD) lactations and an average of $161 \pm 117$ DIM. Any cow with clinical mastitis in single or multiple quarters were treated with antibiotics after sampling. About 110 $\mathrm{mL}$ of foremilk samples was collected manually from individual quarters in 3 steps: $50 \mathrm{~mL}$ of strict foremilk before udder cleaning, taken within $60 \mathrm{~s}$ from all quarters; $50 \mathrm{~mL}$ of foremilk samples after cleaning the teats with warm water containing Iodophor LF12 solution; followed by an aseptic sample for culture after dipping 
the teats in Iodophor LF12 solution and cleaned with a $70 \%$ alcohol-soaked gauze (Khatun et al., 2019). Several cows were sampled on several days as a result of the EC-threshold criterion imposed $(7$ cows $\times 2$ times, 5 cows $\times 3$ times, 4 cows $\times 5$ times, and 1 cow $\times 6$ times). One cow had only 3 functional quarters and this resulted in 686 samples from 48 cows for the laboratory analysis and 343 samples for the culture test.

\section{Laboratory Analysis}

Milk samples collected in the first 2 steps (BME and AME) were analyzed for SCC, total IgG, LDH activity, and SA measurements. The procedures of SCC and LDH activity measurements are described in Khatun et al. (2019).

$S C C$. The SCC was quantified using the principles of laser-based flow cytometry following the manufacturer's protocol (Bentley 2000 Instruments). A Bentley 2000 Autoanalyzer was used to measure SCC (cells $\times$ $1,000 / \mathrm{mL})$.

Total IgG Detection. The procedure to detect total IgG is described in Hernández-Castellano et al. (2017). In brief, total IgG concentration was measured using a commercial ELISA kit specific for bovine IgG (Bethyl Laboratories). Samples were blocked in 5\% fish skin gelatin (Sigma-Aldrich) diluted in double-distilled water. Samples were diluted in wash buffer $(50 \mathrm{mM}$ Tris, $0.14 \mathrm{M} \mathrm{NaCl}, 0.05 \%$ Tween 20, adjusted to $\mathrm{pH}$ 8.0) to ensure that samples were within the range of the standard curve. The standard curve was adjusted to $400,300,150,75,37.5,18.75$, and $9.375 \mathrm{ng} / \mathrm{mL}$. Absorbance measurements were read on the Synergy Mx plate reader (Bio Tec Instruments). The inter- and intraassay coefficients of variation were $\sim 3$ and $\sim 8 \%$, respectively. The minimum detectable concentration was $9.375 \mathrm{ng} / \mathrm{mL}$ and samples were performed in duplicate.

LDH Activity. The LDH was measured by a commercial kit LDH IFCC (Axon Lan AG) and an automated analyzer (Cobas Mira, Roche Diagnostics) with minimum detectable activity $5(\mathrm{U} / \mathrm{L})$.

$S A$ Measurement. The concentration of SA in milk samples was analyzed by ELISA using a bovine-specific commercial kit (Bethyl Laboratories) according to the manufacturer's instructions. Milk samples were diluted in wash buffer ( $50 \mathrm{~m} M$ Tris, $0.14 M \mathrm{NaCl}, 0.05 \%$ Tween 20 , adjusted to $\mathrm{pH} 8.0$ ) to ensure the samples were in range of the standards. Absorbance measurements were read on the Synergy Mx plate reader (BioTek Instruments). The standard curve was 400, 200, 100, 50, 25, 12.5 , and $6.25(\mathrm{ng} / \mathrm{mL})$, and the limit of detection was $6.25 \mathrm{ng} / \mathrm{mL}$. The inter- and intraassay coefficients of variation were 4.58 and $6.99 \%$, respectively. All analyses were performed in duplicate.

Bacteriological Culture. The aseptic milk samples collected on the third step were used for bacteriological culture (Khatun et al., 2019). Briefly, gram-positive species were identified by their growth in sheep blood agar, Enterococcal agar, Rambach agar, bile esculin test, the Christie-Atkins-Munch-Petersen (CAMP) test, and the leukocyte alkaline phosphatase test. Gramnegative coliforms were identified by their growth on sheep blood agar, MacConkey's agar, Gram staining, and potassium hydroxide (slime) test. Samples that did not yield microbial growth following $48 \mathrm{~h}$ of incubation were classified as control (no growth). Isolation of 2 or more bacteria genera from the same sample was considered as nondiagnostic or mixed.

\section{Statistical Analysis}

Data were analyzed using ASReml-R version 4 (Butler et al., 2017) built under $\mathrm{R}$ version 3.5.2 (https:// www.r-project.org), in the form of mixed models as described below. As the distributions of SCC, IgG, LDH, and SA were positively skewed, they were log (base e) transformed before analysis to stabilize the variance and achieve normality of the outcome variables, or to reduce the leverage of very large values when used as explanatory variables. In total, 662 quarter observations were included in the analysis but due to insufficient volume to measure SCC in 24 milk samples, those observations were not possible to include in SCC analysis.

Prediction of IgG Transmission from Blood into Milk by $\mathbf{L D H}$ and $S A$. To compare the IgG transmission from blood into milk the following linear mixed model (LMM) was used:

$$
\begin{gathered}
\ln (\operatorname{IgG})=\beta_{0}+\beta_{1} \ln (\mathrm{LDH})+\beta_{2} \ln (\mathrm{SA}) \\
+s[\ln (\mathrm{LDH})]+u_{C}+u_{C Q}+\varepsilon,
\end{gathered}
$$

where $\ln (\operatorname{Ig} G)=\log ($ base $e$ ) transformed $\operatorname{IgG} ; \ln (\mathrm{LDH})$ $=\log ($ base $e$ ) transformed lactate dehydrogenase as fixed effects together with nonlinear spline term (Verbyla et al., 1999) $s[\ln (\mathrm{LDH})] ; \ln (\mathrm{SA})=\log ($ base $e)$ transformed serum albumin as fixed effect (nonlinear spline was not significant); $\beta_{0}$ is the constant; $\beta_{1}$ and $\beta_{2}$ specify the overall linear effects of the variables; $u_{C}$ and $u_{C Q}$ are cow and quarter nested within cow as random effects; and $\varepsilon$ is a random error.

Comparison of LDH Activity and SA to Predict Gram-Positive and Gram-Negative IMI. To compare the effectiveness of LDH activity and SA to 
predict gram-positive IMI versus control, and gramnegative IMI versus control, both of these variables after log-transformation were standardized or re-scaled; that is, $x^{\prime}=(x-\bar{x}) / S D_{x}$, to compare variables across different scales, using the scale function in $\mathrm{R}$. The standardized LDH activity and SA were assessed individually, as well as separate models for LDH and SA to predict gram-positive versus gram-negative IMI (i.e., 4 models). The following logistic generalized linear mixed model (GLMM) was fitted to the IMI status data, incorporating a spline function to allow for a possible nonlinear response (on the log-odds scale) of the explanatory variable:

$$
\ln [\pi /(1-\pi)]=\beta_{0}+\beta_{1} x^{\prime}+s\left(x^{\prime}\right)+u_{C}+u_{C Q},
$$

where $\pi$ is the probability of mastitis (gram-positive IMI vs. control, or gram-negative IMI vs. control) and $x^{\prime}$ is the standardized $\ln (\mathrm{LDH})$ and $\ln (\mathrm{SA})$. Each is included as a fixed linear effect, together with a nonlinear spline term, $s\left(x^{\prime}\right)$, specified as a random effect in the model, and also included $u_{C}$ and $u_{C Q}$ as cow and quarter nested within cow as random effects. Rescaling allowed displaying 2 predictors and 2 response variables with the corresponding fitted values on the same plot, allowing comparison of their effects.

Assessment of Combined SCC-LDH and SCC$S A$ to Predict Gram-Positive and Gram-Negative IMI by Receiver Operating Characteristic Curve. The following logistic GLMM were fitted separately to the gram-positive and gram-negative IMI status data with model terms as described in the previous model:

$\ln [\pi /(1-\pi)]=\beta_{0}+\beta_{1} \ln (\mathrm{SCC})+\beta_{2} \ln (\mathrm{LDH})+u_{C}+u_{C Q}$,

and

$$
\ln [\pi /(1-\pi)]=\beta_{0}+\beta_{1} \ln (\mathrm{SCC})+\beta_{2} \ln (\mathrm{SA})+u_{C}+u_{C Q},
$$

where $\pi$ is the probability that a particular quarter is gram-positive or gram-negative IMI versus control; $\ln (\mathrm{SCC}), \ln (\mathrm{LDH})$, and $\ln (\mathrm{SA})$ are predictors, as a fixed effect; and $u_{C}$ and $u_{C Q}$ are the random cow and quarter nested within cow as random effects. Using output from these fitted models, construction of receiver operating characteristic (ROC) curves was then performed using the pROC package in $\mathrm{R}$ (version 4.0.2) (Robin et al., 2011) as described by Khatun et al. (2019). In brief, the ROC assessment graphically illustrates the diagnostic test as a plot of sensitivity (Se) versus the complement of specificity (Sp; $1-\mathbf{S p}$ ) for varying cut points (Hanley and McNeil, 1982). The generated area under the curve (AUC) value from the ROC curve is used to measure diagnostic test performance, classified as excellent (0.9 to 1$)$, good (0.8 to 0.9$)$, fair (0.7 to 0.8$)$, poor (0.6 to 0.7), or fail (0.5 to 0.6, Swets, 1988). The AUC values of SCC-LDH versus SCC-SA for gram-positive and gram-negative IMI were compared by using the roc.test (DeLong's test for 2 correlated ROC curves) in the pROC package. Test performance was also evaluated using Youden's index $(J=\mathrm{Se}+\mathrm{Sp}-1)$, selecting a cutoff point at which the index is maximized (Ruopp et al., 2008).

Correlation. To estimate the correlations between pairs of variables (on the logarithmic scale) adjusting for the fixed effects, the following bivariate linear mixed models were fitted to all possible 6 pairs of variables ( $\mathrm{SCC}$ vs. IgG, SCC vs. LDH, SCC vs. SA, IgG vs. LDH, IgG vs. SA, and LDH vs. SA):

$\left(\begin{array}{l}y_{1} \\ y_{2}\end{array}\right)=\left(\begin{array}{l}\mu_{1} \\ \mu_{2}\end{array}\right)+\left(\begin{array}{l}\text { Culture }_{1} \\ \text { Culture }_{2}\end{array}\right)+\left(\begin{array}{l}\mathrm{Cow}_{1} \\ \mathrm{Cow}_{2}\end{array}\right)+\left(\begin{array}{c}\mathrm{Cow} \cdot \text { Quarter }_{1} \\ \mathrm{Cow} \cdot \text { Quarter }_{2}\end{array}\right)+\left(\begin{array}{l}\varepsilon_{1} \\ \varepsilon_{2}\end{array}\right)$

where $y_{1}$ and $y_{2}$ are the pair of variables as listed above (log-transformed), $\mu_{1}$ and $\mu_{2}$ are the overall trait means, Culture $_{1}$ and Culture $_{2}$ are the fixed effects for each variable of the gram-positive and gram-negative bacteria (e.g., Aerococcus sp., Bacillus, CNS, coagulase-positive Staphylococcus, coliform, Corynebacterium sp., Enterococcus faecalis, environmental Streptococcus, Streptococcus agalactiae, Streptococcus dysgalactiae, Streptococcus uberis, and Trueperella pyogenes) for variables 1 and 2 , with random effects $\mathrm{Cow}_{1}, \mathrm{Cow}_{2}$, Cow.Quarter 1 , Cow.Quarter 2 , and random errors $\varepsilon_{1}$ and $\varepsilon_{2}$, with correlations also between the pairs of random effects. This is specified through the following models for the variancecovariance structure, where it is assumed that

$$
\begin{gathered}
\left(\begin{array}{l}
\mathrm{Cow}_{1} \\
\mathrm{Cow}_{2}
\end{array}\right) \sim N\left(\left(\begin{array}{l}
0 \\
0
\end{array}\right),\left(\begin{array}{cc}
\sigma_{C 1}^{2} & \sigma_{C 12} \\
\sigma_{C 12} & \sigma_{C 2}^{2}
\end{array}\right)\right), \\
\left(\begin{array}{c}
\text { Cow } \cdot \text { Quarter }_{1} \\
\text { Cow } \cdot \text { Quarter }_{2}
\end{array}\right) \sim N\left(\left(\begin{array}{l}
0 \\
0
\end{array}\right),\left(\begin{array}{cc}
\sigma_{C Q 1}^{2} & \sigma_{C Q 12} \\
\sigma_{C Q 12} & \sigma_{C Q 2}^{2}
\end{array}\right)\right), \text { and } \\
\left(\begin{array}{l}
\varepsilon_{1} \\
\varepsilon_{2}
\end{array}\right) \sim N\left(\left(\begin{array}{l}
0 \\
0
\end{array}\right),\left(\begin{array}{cc}
\sigma_{\varepsilon 1}^{2} & \sigma_{\varepsilon 12} \\
\sigma_{\varepsilon 12} & \sigma_{\varepsilon 2}^{2}
\end{array}\right)\right) .
\end{gathered}
$$

Using the REML estimates of variance and covariance components, the correlation between a pair of traits 
$\left(y_{1}, y_{2}\right)$, adjusting for the fixed effects, is calculated as follows:

$$
\begin{aligned}
& r_{12}=\frac{\operatorname{cov}\left(y_{1}, y_{2}\right)}{\left[\operatorname{var}\left(y_{1}\right) \times \operatorname{var}\left(y_{2}\right)\right]^{1 / 2}}= \\
& \frac{\hat{\sigma}_{C 12}+\hat{\sigma}_{C Q 12}+\hat{\sigma}_{\varepsilon 12}}{\left[\left(\hat{\sigma}_{C 1}^{2}+\hat{\sigma}_{C Q 1}^{2}+\hat{\sigma}_{\varepsilon 1}^{2}\right) \times\left(\hat{\sigma}_{C 2}^{2}+\hat{\sigma}_{C Q 2}^{2}+\hat{\sigma}_{\varepsilon 2}^{2}\right)\right]^{1 / 2}} .
\end{aligned}
$$

In the 3 covariance matrices, the diagonal terms represent the variances $\left(\sigma^{2}\right)$ for each trait, whereas the offdiagonal terms represent the covariances $(\sigma)$ between the traits. Model fitting was conducted using ASReml $\mathrm{R}$ version 4 (Butler et al., 2017). From these pairwise correlations, a correlation matrix of all 4 traits was constructed and tested for validity (positive definite form). (Note that it was not possible to fit a multivariate model with 4 traits simultaneously in ASReml-R).

Difference in $S C C, I g G, L D H$, and $S A B e-$ tween Gram-Positive and Gram-Negative IMI. The differences in gram-positive and gram-negative IMI were assessed using the following linear mixed model:

$$
\begin{gathered}
Y=\beta_{0}+\text { culture }+ \text { DIM }+ \text { culture } \times \text { DIM } \\
+u_{C}+u_{C Q}+\varepsilon,
\end{gathered}
$$

where $Y$ is the response variable $\ln (\mathrm{SCC}), \ln (\operatorname{Ig} \mathrm{G})$, $\ln (\mathrm{LDH})$, or $\ln (\mathrm{SA})$; culture = gram-positive, gramnegative IMI, and control as fixed effect; DIM = early $(0$ to $100 \mathrm{~d})$, mid $(101$ to $200 \mathrm{~d})$, and late $(>200 \mathrm{~d})$ lactation period as a fixed effect, with culture $\times$ DIM being the interaction; $u_{C}$ and $u_{C Q}$ are the cow and quarter nested within cow as random effects, and $\varepsilon$ is the random error. Predicted means were calculated with corresponding standard error.

Principal Component Analysis. To explore all 4 milk parameters [i.e., $\ln (\mathrm{SCC}), \ln (\mathrm{IgG}), \ln (\mathrm{LDH})$, and $\ln (\mathrm{SA})]$ simultaneously, a principal component analysis (PCA) was undertaken on these data (variables scaled to have a unit standard deviation), using the prcomp function in R. Loadings of the first 2 principal components were interpreted.

Principal Component Scores Comparing Gram-Positive and Gram-Negative IMI. The following linear mixed model was used to predict mastitis types based on principal component (PC) scores:

$$
\begin{aligned}
Y=\beta_{0} & + \text { culture }+\left(\beta_{\text {DIM }}+\gamma_{\text {Culture.DIM }}\right) \text { DIM } \\
& +s(\mathrm{DIM})+u_{C}+u_{C Q}+\varepsilon
\end{aligned}
$$

where $Y$ is the response variable, either $\mathrm{PC} 1$ scores or PC2 scores; DIM = days in milk as linear fixed effect together with spline term $s$ (DIM) to allow for a nonlinear response over the lactation; $\beta_{\mathrm{DIM}}$ specifies the overall linear effect of DIM; $\gamma_{\text {Culture.DIM }}$ is used to specify the culture $\times$ DIM interaction; and other terms are as defined in previous models. Predicted means were calculated with corresponding standard error.

Effect of Milk Ejection on SCC, IgG, LDH Activity, and $S A$. The differences in 2 different milk samples collected BME versus AME were assessed using the following linear mixed model:

$$
\begin{gathered}
Y=\beta_{0}+\text { time }+\beta_{\mathrm{DIM}} \mathrm{DIM}+s(\mathrm{DIM}) \\
+u_{C}+u_{C Q}+\varepsilon,
\end{gathered}
$$

where $Y$ is the response variable $[\ln (\mathrm{SCC}), \ln (\operatorname{Ig} \mathrm{G})$, $\ln (\mathrm{LDH}), \ln (\mathrm{SA})]$, time $=\mathrm{BME}$ versus $\mathrm{AME}$ as a fixed effect, and other terms are as defined previously. Predicted means were calculated with corresponding standard error.

\section{RESULTS}

\section{Bacteriological Culture and Electrical Conductivity}

The gold standard of this study was bacteriological culture. Out of 343 bacteriological culture tests, 169 quarters were culture positive (e.g., gram-positive, gram-negative, and mixed growth) and 174 quarters had no growth (control). There were $157(45.77 \%)$ gram-positive quarter samples $(\mathrm{n}=39$ cows), $6(1.75 \%)$ gram-negative quarter samples $(\mathrm{n}=4$ cows $)$, and 174 $(50.73 \%)$ control quarter samples $(\mathrm{n}=41$ cows $)$. Each culture was used as a gold standard for individual quarter milk samples collected in 2 steps, resulting in a doubling of the number of the gram-positive, gramnegative, and control samples in the analysis. Among the gram-positive, gram-negative, and control quarters, 121,3 , and 21 quarters had $>7.5 \mathrm{mS} / \mathrm{cm} \mathrm{EC}$ and 35 , 3 , and 145 quarters had $<7.5 \mathrm{mS} / \mathrm{cm} \mathrm{EC}$, respectively.

\section{Prediction of IgG Transmission from Blood into Milk by LDH and SA}

Overall, both SA $(P<0.001)$ and LDH $(P=0.001)$ were positively associated with IgG transmission from blood into milk based on combined BME and AME milk samples from the LMM (Eq. [1]; Table 1). The positive association of $\operatorname{IgG}$ with $\mathrm{LDH}$ was nonlinear (Figure 1), whereas the association was linear with SA 


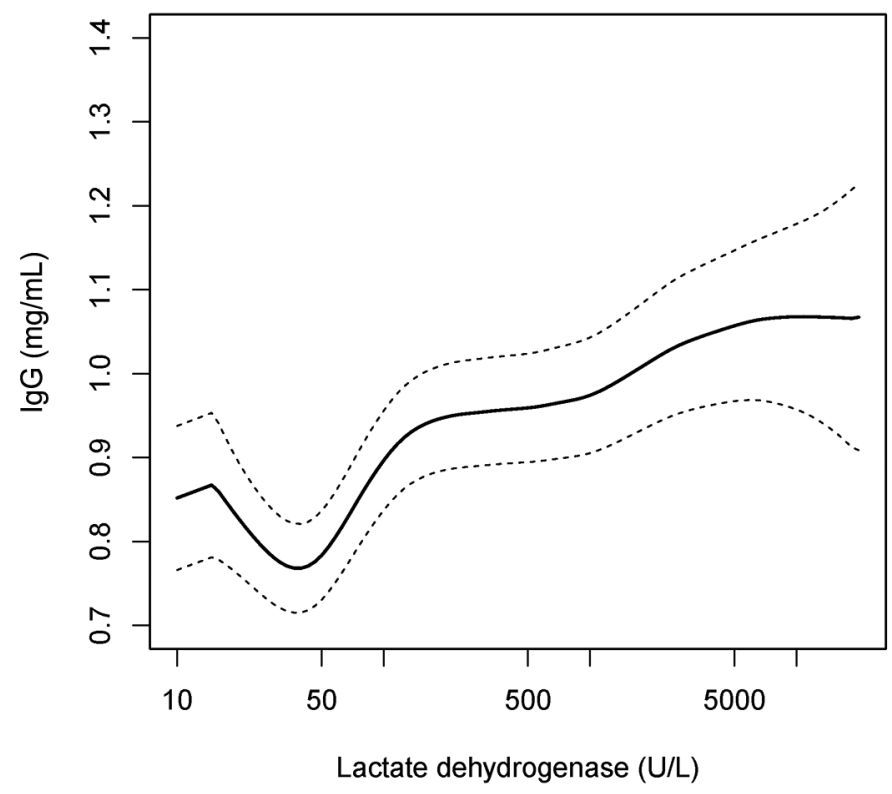

Figure 1. Prediction of $\operatorname{IgG}(\mathrm{mg} / \mathrm{mL}$, estimated value $\pm \mathrm{SE})$ transmission by lactate dehydrogenase $(\mathrm{LDH}, \mathrm{U} / \mathrm{L}$, plotted on a logarithmic $x$-axis scale). This mixed model included $\ln (\mathrm{LDH})$ and $\ln ($ serum albumin, SA) as fixed effects together with nonlinear term $\ln (\mathrm{LDH})$, with cow and quarter nested within cow as random effects $(\mathrm{n}=662$ quarters). Because of positively skewed distributions, IgG, LDH, and SA data were log-transformed.

(on $\log$ scale, Figure 2). Only SA had significant ( $P$ $<0.001)$ positive associations with IgG transmission based on separate BME and AME samples.

\section{Comparison of LDH Activity and SA to Predict Gram-Positive and Gram-Negative IMI}

After rescaling (standardizing), $\ln (\mathrm{LDH})$ activity and $\ln (\mathrm{SA})$ showed positive associations with the probability of gram-positive IMI versus control and gram-negative IMI versus control (Figure 3) based on the GLMM in Eq. [2]. The standardized $\ln (\mathrm{SA})(P=0.001)$ and

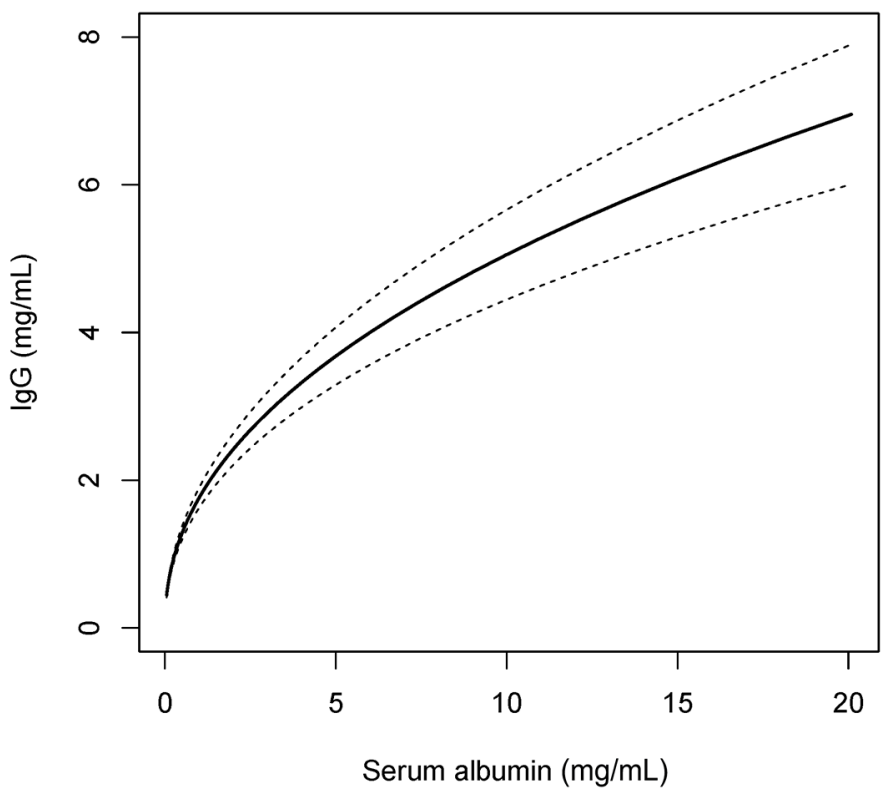

Figure 2. Prediction of IgG $(\mathrm{mg} / \mathrm{mL}$, estimated value $\pm \mathrm{SE})$ transmission by serum albumin (SA, $\mathrm{mg} / \mathrm{mL}$ ). This mixed model included $\ln$ (lactate dehydrogenase, $\mathrm{LDH}$ ) and $\ln (\mathrm{SA})$ as fixed effects together with nonlinear term $\ln (\mathrm{LDH})$, with cow and quarter nested within cow as random effects $(\mathrm{n}=662$ quarters). Because of positively skewed distributions, IgG, LDH, and SA data were log-transformed.

standardized $\ln (\mathrm{LDH})(P=0.008)$ had similar gramnegative IMI prediction ability. However, standardized $\ln (\mathrm{SA})(P=0.008)$ had better gram-positive IMI prediction ability than standardized $\ln (\mathrm{LDH})(P=0.058)$.

\section{Assessment of Individual and Combined SCC-LDH and SCC-SA to Predict Gram-Positive and Gram-Negative IMI by ROC Curve}

The combined SCC-LDH and SCC-SA (GLMM in Eq. [3]) had significantly greater IMI prediction ability than individual $\ln (\mathrm{SCC}), \ln (\mathrm{LDH})$ and $\ln (\mathrm{SA})$ sepa-

Table 1. Comparison of lactate dehydrogenase (LDH) and serum albumin (SA) to predict IgG transmission from blood into milk by linear mixed model ${ }^{1}$

\begin{tabular}{|c|c|c|c|c|}
\hline Item $^{2}$ & Coefficient $\pm \mathrm{SE}$ & $P$-value & Cow $\left(\sigma^{2}\right)^{3}$ & Quarter $\left(\sigma^{2}\right)^{3}$ \\
\hline \multicolumn{5}{|l|}{$\mathrm{BME}+\mathrm{AME}(\mathrm{n}=662)$} \\
\hline $\mathrm{LDH}(\log$ base $e, \mathrm{U} / \mathrm{L})$ & $0.05 \pm 0.01$ & 0.001 & $0.18 \pm 0.04$ & $0.02 \pm 0.00$ \\
\hline $\mathrm{SA}(\log$ base $e, \mathrm{mg} / \mathrm{mL})$ & $0.46 \pm 0.03$ & $<0.001$ & & \\
\hline \multicolumn{5}{|l|}{$\operatorname{BME}(\mathrm{n}=331)$} \\
\hline $\mathrm{LDH}(\log$ base $e, \mathrm{U} / \mathrm{L})$ & $0.02 \pm 0.02$ & 0.402 & $0.19 \pm 0.04$ & $0.02 \pm 0.00$ \\
\hline $\mathrm{SA}(\log$ base $e, \mathrm{mg} / \mathrm{mL})$ & $0.50 \pm 0.03$ & $<0.001$ & & \\
\hline \multicolumn{5}{|l|}{$\operatorname{AME}(\mathrm{n}=331)$} \\
\hline LDH (log base $e, \mathrm{U} / \mathrm{L})$ & $0.09 \pm 0.02$ & 0.005 & $0.17 \pm 0.04$ & $0.06 \pm 0.04$ \\
\hline $\mathrm{SA}(\log$ base $e, \mathrm{mg} / \mathrm{mL})$ & $0.42 \pm 0.04$ & $<0.001$ & & \\
\hline
\end{tabular}

${ }^{1}$ Linear mixed models to predict IgG including LDH and SA, with random effect estimates for each cow and cow-quarter.

${ }^{2} \mathrm{BME}=$ sampling times before ejection; $\mathrm{AME}=$ sampling times after ejection.

${ }^{3} \sigma^{2}=$ variance estimate \pm SE. 
A

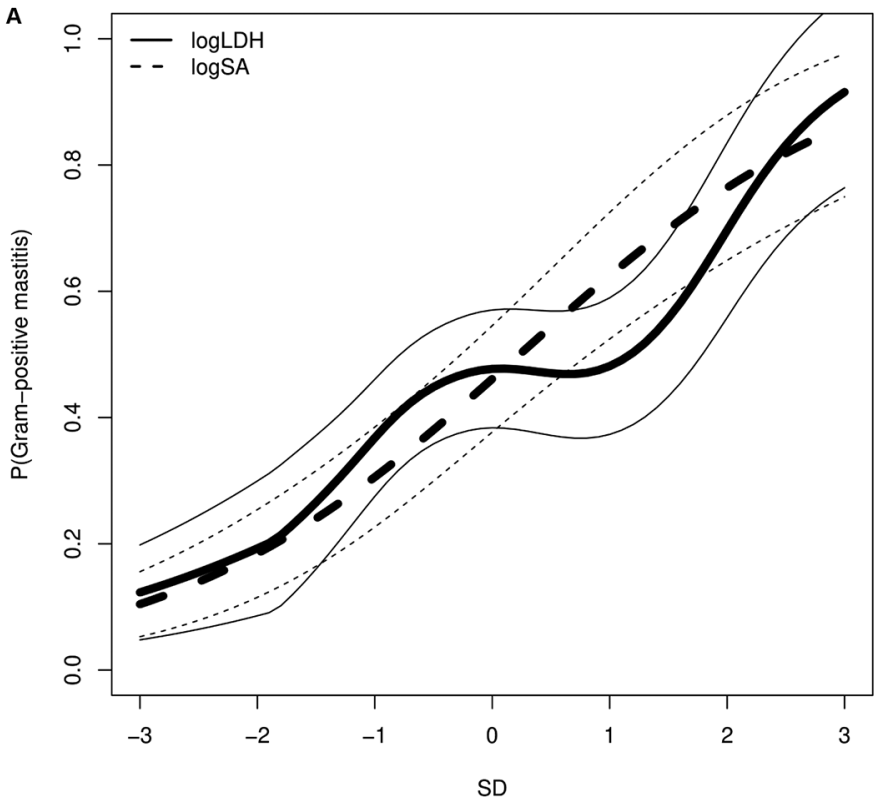

B

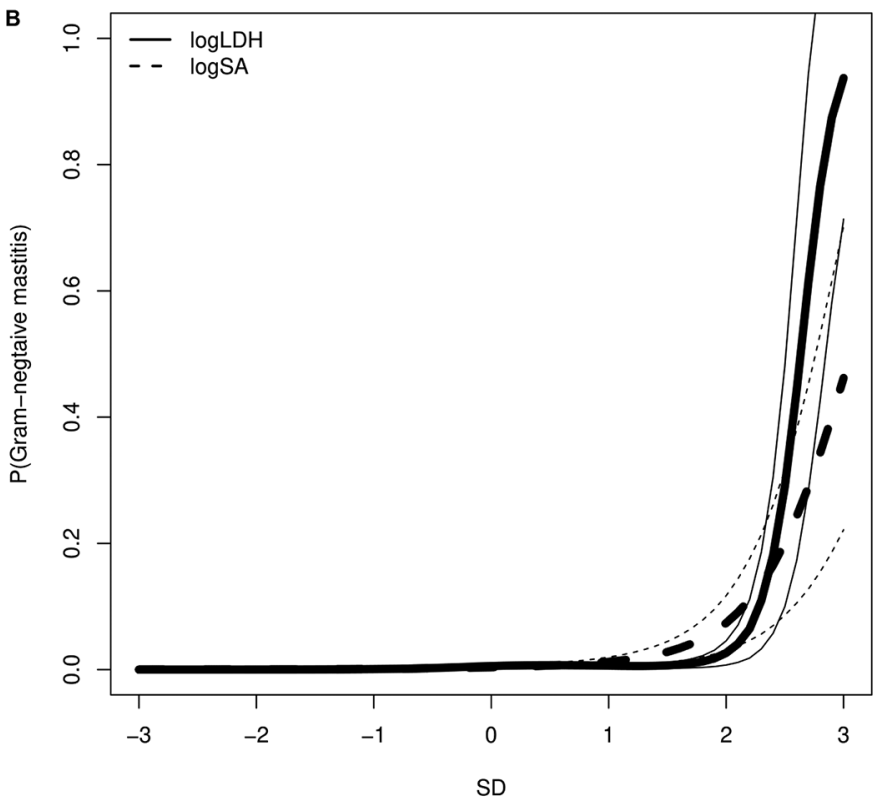

Figure 3. Comparison of probabilities of mastitis (predicted value $\pm \mathrm{SE}$ ) for varying lactate dehydrogenase ( $\mathrm{LDH}$, solid lines) and serum albumin (SA, dashed lines), with separate predictions for grampositive $(\mathrm{n}=304)$, gram-negative IMI $(\mathrm{n}=12)$ and control $(\mathrm{n}=334)$ quarters. Each of the 4 logistic models included standardized LDH or standardized SA (expressed as number of SD away from the mean, after log-transformation) as fixed effects, with cow or quarter nested within cow as random effects, and with a model for gram-positive versus control, and gram-negative versus control. Because of positively skewed distributions, LDH and SA data were log-transformed.

rately (Table 2). In the ROC evaluation, we obtained excellent (AUC >0.9) gram-positive versus control and gram-negative versus control IMI prediction ability for both SCC-LDH and SCC-SA. The SCC-LDH vs. SCC-
SA had lower gram-positive $(\mathrm{AUC}=0.984$ vs. $0.986, P$ $=0.010)$ but similar gram-negative $(\mathrm{AUC}=0.995 \mathrm{vs}$. $0.998, P=0.134)$ IMI prediction ability, as specified by the AUC values, respectively.

\section{Correlations}

In bivariate mixed model analysis, after adjusting for fixed effects (Eq. [4]), there were very strong positive correlations (all calculated on a log scale) between LDH activity with SCC $(\mathrm{r}=0.80, P<0.001)$ followed by LDH with SA $(\mathrm{r}=0.70, P<0.001$; Table 3$)$.

\section{Difference in SCC, IgG, LDH, and SA Between Gram-Positive and Gram-Negative IMI}

Based on the LMM in Eq. [5], the mean SCC, IgG, $\mathrm{LDH}$, and SA between gram-positive and gram-negative IMI in early (0-100 DIM), mid (101-200 DIM), and late (>200 DIM) lactation period are presented in Table 4. Overall., the differences in SCC, IgG, LDH, and SA in gram-positive and gram-negative IMI type were significant in the early- to mid-lactation period. There was a significant interaction between DIM and pathogen type for SCC $(P<0.001)$, IgG $(P<0.001)$, LDH activity $(P<0.001)$, and SA $(P<0.001)$. The ranges of DIM included in the analysis for different IMI type are presented in Table 5 .

Based on BME and AME together and AME samples, gram-negative IMI had significantly greater $(P<$ 0.05) SCC than control in the early-lactation period. However, based on BME and AME together, and BME samples, gram-negative IMI had significantly lower SCC than control and gram-positive IMI in the mid-lactation period. The gram-negative IMI had significantly $(P<$ $0.05)$ greater IgG than control and gram-positive IMI in the early- and mid-lactation period in all sample types (e.g., BME and AME together, only BME and only AME).

Based on BME and AME together, and only AME samples, the LDH was significantly $(P<0.05)$ greater in gram-negative IMI than control and gram-positive IMI in the early- and mid-lactation period. Based on only BME, gram-negative IMI had significantly $(P<$ $0.05)$ greater LDH than control and gram-positive IMI in the early-lactation period.

Based on BME and AME together, the SA was significantly $(P<0.05)$ greater in gram-negative IMI than control in early- and mid-lactation period, also than gram-positive IMI in early-lactation period. Gram-negative IMI had significantly greater SA than control and gram-positive IMI in early- and mid-lactation period when comparing the only BME and only AME samples. 
Table 2. Analysis of receiver operating characteristic curves, sensitivity (Se), and specificity (Sp) at optimum cutoff value for prediction of gram-positive and gram-negative IMI based on model (logistic generalized linear mixed $\operatorname{model}^{1}$ )

\begin{tabular}{llcccc}
\hline Predictor $^{2}$ & Culture $^{3}$ & $\mathrm{AUC}^{4}(95 \% \mathrm{CI})$ & $\mathrm{Se}$ & $\mathrm{Sp}$ & $P$-value \\
\hline SCC-LDH & Gram-positive & $0.984(0.978-0.991)$ & 0.963 & 0.918 & $0.010^{5}$ \\
& Gram-negative & $0.995(0.990-1.000)$ & 1.000 & 0.988 & $0.134^{5}$ \\
SCC-SA & Gram-positive & $0.986(0.980-0.992)$ & 0.963 & 0.924 & \\
& Gram-negative & $0.998(0.994-1.000)$ & 1.000 & 0.994 & $<0.001^{6}$ \\
& Gram-positive & $0.649(0.606-0.692)$ & 0.712 & 0.568 & $0.013^{6}$ \\
LDH & Gram-negative & $0.806(0.655-0.957)$ & 0.700 & 0.827 & $<0.001^{6}$ \\
& Gram-positive & $0.608(0.564-0.652)$ & 0.607 & 0.565 & $0.046^{6}$ \\
SA & Gram-negative & $0.883(0.773-0.993)$ & 0.800 & 0.848 & $<0.001^{5}$ \\
& Gram-positive & $0.608(0.564-0.652)$ & 0.427 & 0.726 & $0.037^{5}$ \\
\hline
\end{tabular}

${ }^{1}$ Logistic generalized linear mixed models included 2 variables (SCC, and lactate dehydrogenase activity or serum albumin), with cow and cow-quarter random effects. In both gram-positive and gram-negative mastitis, the control was quarters without any bacterial growth $(\mathrm{n}=329)$.

${ }^{2} \mathrm{LDH}=$ lactate dehydrogenase; $\mathrm{SA}=$ serum albumin.

${ }^{3}$ Culture: gram-negative $=$ IMI caused by gram-negative coliform bacteria $(\mathrm{n}=10)$; gram-positive $=$ IMI caused by gram-positive bacteria $(\mathrm{n}=295)$.

${ }^{4} \mathrm{AUC}=$ area under the curve.

${ }^{5}$ Comparison of AUC values with combined SCC-SA.

${ }^{6}$ Comparison of AUC values with combined SCC-LDH.

\section{$P C A$}

Exploring associations between all 4 parameters, based on the PCA, $90 \%$ of the variation in the 4-dimensional space was accounted for by the first $2 \mathrm{PC}$ (PC1 and PC2; Table 6). In PC1, all 4 variables had approximately equal positive loadings $(\sim 0.5)$ and is effectively an average of these 4 parameters. In PC2, there was a contrast between a higher impact positive SCC loading versus negative IgG loading and a lesser impact positive LDH activity versus negative SA loading. From the plot of $\mathrm{PC} 1$ versus $\mathrm{PC} 2$, there is evidence of clustering of results on types of IMI (Figure 4).

\section{Association Between PC Scores and Gram-Positive and Gram-Negative IMI}

Based on the analysis of PC1 scores using the LMM (Eq. [6]), gram-negative IMI had significantly $(P<$ $0.05)$ greater scores than control and gram-positive IMI (Table 7). Given the loadings of PC1, this indicates that gram-negative IMI samples tend to have higher values of $\mathrm{SCC}, \mathrm{IgG}, \mathrm{LDH}$, and $\mathrm{SA}$, and hence are useful to predict gram-negative IMI. Based on $\mathrm{PC} 2$ scores, gram-negative IMI also had significantly $(P<$ $0.05)$ lower scores than control and gram-positive IMI. Hence, samples with lower PC2 scores (i.e., greater IgG but lower SCC) were more likely to be associated with coliform IMI. On the other hand, higher PC2 scores (i.e., greater SCC but lower $\operatorname{IgG}$ ) were more likely in gram-positive IMI samples.

\section{Effect of Milk Ejection on SCC, IgG, LDH Activity, and SA}

Based in the LMM specified by Eq. [7], the milk ejection had significant effects on SCC, IgG, LDH activity, and $\mathrm{SA}$ in mastitic quarters caused my gram-positive and gram-negative bacteria as well as in control (Table 8). Overall, the mastitic quarters had greater SCC, IgG, $\mathrm{LDH}$, and SA than the healthy quarters, particularly in BME samples. When comparing without separating mastitic and healthy quarters, the BME samples had significantly greater SCC, LDH, IgG, and SA than the

Table 3. Model-based correlations ( \pm SE) between SCC, IgG, lactate dehydrogenase (LDH), and serum albumin (SA) estimated from bivariate linear mixed model ( $\mathrm{n}=642$ quarters)

\begin{tabular}{lcccc}
\hline Item & $\ln (\mathrm{SCC})$ & $\ln (\mathrm{IgG})$ & $\ln (\mathrm{LDH})$ & $\ln (\mathrm{SA})$ \\
\hline $\ln (\mathrm{SCC})$ & 1 & & & \\
$\ln (\mathrm{IgG})$ & $0.39 \pm 0.07^{* * *}$ & 1 & 1 & \\
$\ln (\mathrm{LDH})$ & $0.80 \pm 0.02^{* * *}$ & $0.53 \pm 0.05^{* * *}$ & $0.70 \pm 0.03^{* * *}$ & 1 \\
$\ln (\mathrm{SA})$ & $0.47 \pm 0.05^{* * *}$ & $0.62 \pm 0.06^{* * *}$ & $0.70 \pm$ \\
\hline
\end{tabular}

${ }^{* * *} P<0.001$ for all correlation coefficients shown. 


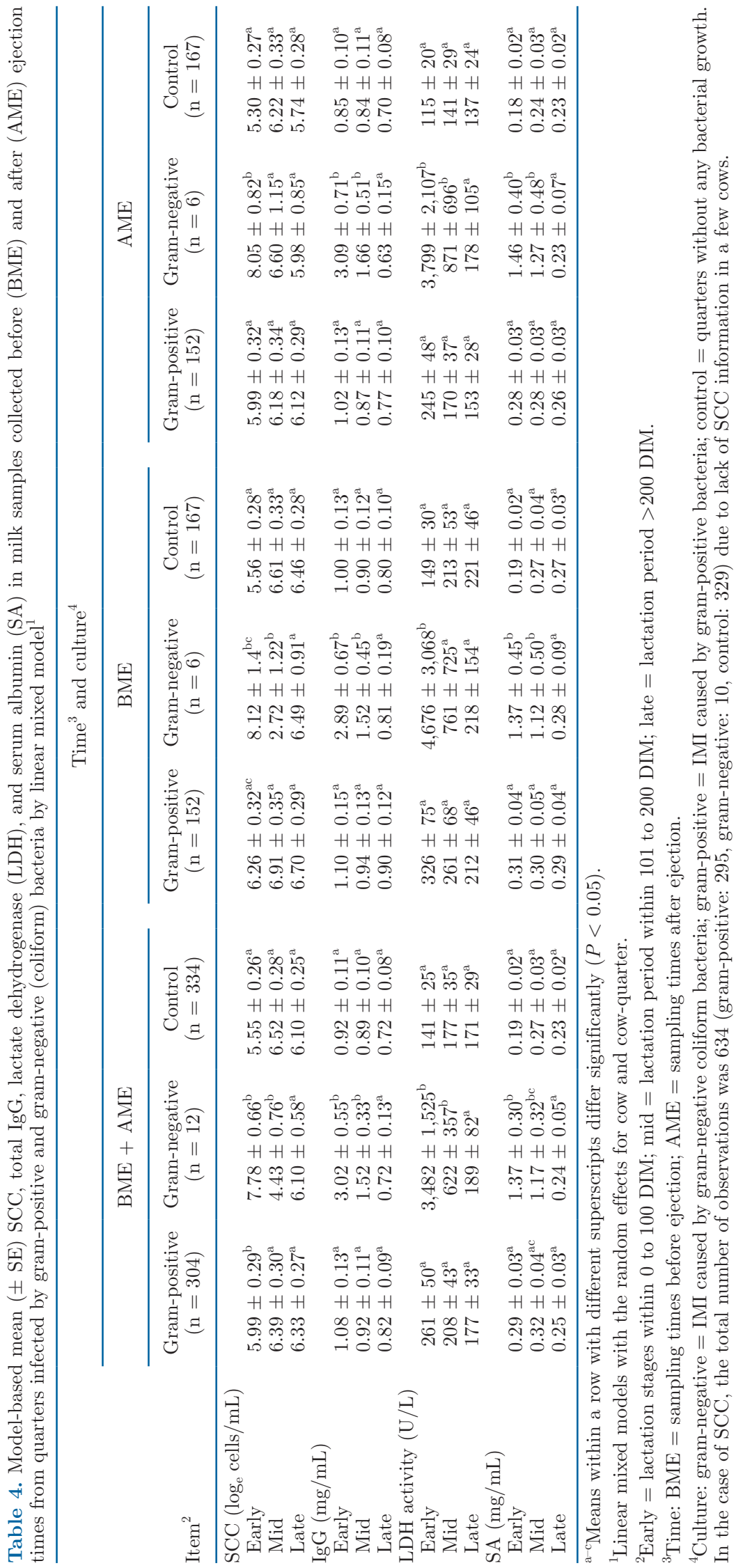


Table 5. Descriptive statistics of DIM for gram-positive and gram-negative IMI compared with control

\begin{tabular}{lcccccc}
\hline & \multicolumn{7}{c}{ DIM } \\
\cline { 2 - 7 } Culture $^{1}$ & Minimum & $\begin{array}{c}\text { First } \\
\text { quarter }\end{array}$ & Median & Mean & $\begin{array}{c}\text { Third } \\
\text { quarter }\end{array}$ & Maximum \\
\hline Control $_{\text {Gram-positive }}$ & 2 & 56 & 124 & 144 & 231 & 398 \\
Gram-negative & 1 & 56 & 179 & 178 & 273 & 459 \\
\hline
\end{tabular}

${ }^{1}$ Culture: gram-negative = IMI caused by gram-negative coliform bacteria; gram-positive = IMI caused by gram-positive bacteria; control = quarters without any bacterial growth .

AME samples (all $P<0.001$ ). In comparison, considering only mastitic quarters, BME samples had significantly greater SCC $(P<0.001), \operatorname{IgG}(P<0.001), \mathrm{LDH}$ activity $(P<0.001)$, and SA $(P=0.010)$ than AME samples. Similar comparison in control quarters also resulted in significant greater SCC $(P<0.001)$, IgG $(P<0.001)$, LDH activity $(P<0.001)$, and SA $(P=$ 0.020) in BME than AME samples.

\section{DISCUSSION}

To our knowledge this is the first study that has investigated the suitability of SA concentration and $\mathrm{LDH}$ activity in milk to be used as potential markers of $\operatorname{IgG}$ transmission from blood into milk in vivo in naturally occurring mastitis, and based on that, to distinguish between pathogen types that cause mastitis. Both SA and, in particular, LDH can be analyzed with established laboratory methods, which would allow a potential automatization. In contrast, the exact measurement of IgG by ELISA appears to be more complicated, mostly requiring different steps of sample dilution, and an automatization for on-farm use is likely not possible (Lehmann et al., 2013; Wall et al., 2016). Our study has found that both LDH and SA could be markers of IgG transfer via the blood-milk barrier, and both are suitable to differentiate gram-positive and gramnegative IMI in combination with the SCC results in milk samples. Further, foremilk BME is more informative for better mastitis detection in AMS than AME.

Table 6. Variation explained by principal component (PC) analysis and its component loadings $(\mathrm{n}=634)$

\begin{tabular}{lrr}
\hline Item & PC1 & \multicolumn{1}{c}{ PC2 } \\
\hline Variation explained & 0.74 & 0.15 \\
Variable & & \\
SCC $\left(\log _{e}\right.$, cells $\left./ \mathrm{mL}\right)$ & 0.49 & 0.61 \\
IgG $\left(\log _{e}, \mathrm{mg} / \mathrm{mL}\right)$ & 0.45 & -0.69 \\
Lactate dehydrogenase $\left(\log _{e}, \mathrm{U} / \mathrm{L}\right)$ & 0.54 & 0.28 \\
Serum albumin $\left(\log _{e}, \mathrm{mg} / \mathrm{mL}\right)$ & 0.51 & -0.27 \\
\hline
\end{tabular}

In this study, prediction of IgG using LDH supports previous findings (in experimentally challenged mammary glands) that LDH could be a marker for IgG transfer via the leaky blood-milk barrier in vivo in naturally occurring mastitis (Lehmann et al., 2013). The reason for investigating $\mathrm{SA}$ in this in vivo study is that SA appears earlier than LDH (2 vs. $5 \mathrm{~h}$ ) in experimentally induced mastitis as reported in other studies (Wall et al., 2016; Wellnitz et al., 2016). In addition to the transfer via the blood-milk barrier, both SA and LDH may originate from mammary epithelial cell production that may cause an increase of SA (Shamay et al., 2005), and mammary cell damage may contribute to the increased concentration of LDH in milk (Wellnitz et al., 2016; Cheng et al., 2021). The potential contribution of the 2 sources of SA and LDH may support the possibility to distinguish between IMI-causing pathogen types. The better gram-positive IMI prediction ability of SA than LDH further specifies the utility of SA to differentiate the mastitis type. Our findings demonstrate that SA could be used as an alternative marker to LDH to indicate IgG transfer via the blood-milk barrier. Based on several studies, the combination of multiple sensor information is useful to detect and differentiate mastitis types more efficiently in AMS (Hogeveen et al., 2010; Steeneveld et al., 2015; Hernández-Castellano et al., 2017). In this study, the greater gram-positive and gram-negative IMI prediction ability of combined SCC-LDH and SCC-SA compared with SCC, LDH, and SA alone, supports previous findings (HernándezCastellano et al., 2017; Khatun et al., 2019). Based on similar gram-positive and gram-negative IMI prediction ability by SCC-LDH and SCC-SA, our recommendation is SCC-SA could be the alternate of SCC-LDH to differentiate mastitis type inline in AMS.

Overall, the greater SCC, IgG, LDH, and SA in gramnegative coliform IMI compared with gram-positive IMI might be due to severe damage of the blood-milk barrier allowing abundant migration as found previously in experimentally induced mastitis (Wellnitz et al., 2011; Lehmann et al., 2013; Wall et al., 2016). The greater SCC, IgG, LDH, and SA in coliform IMI com- 


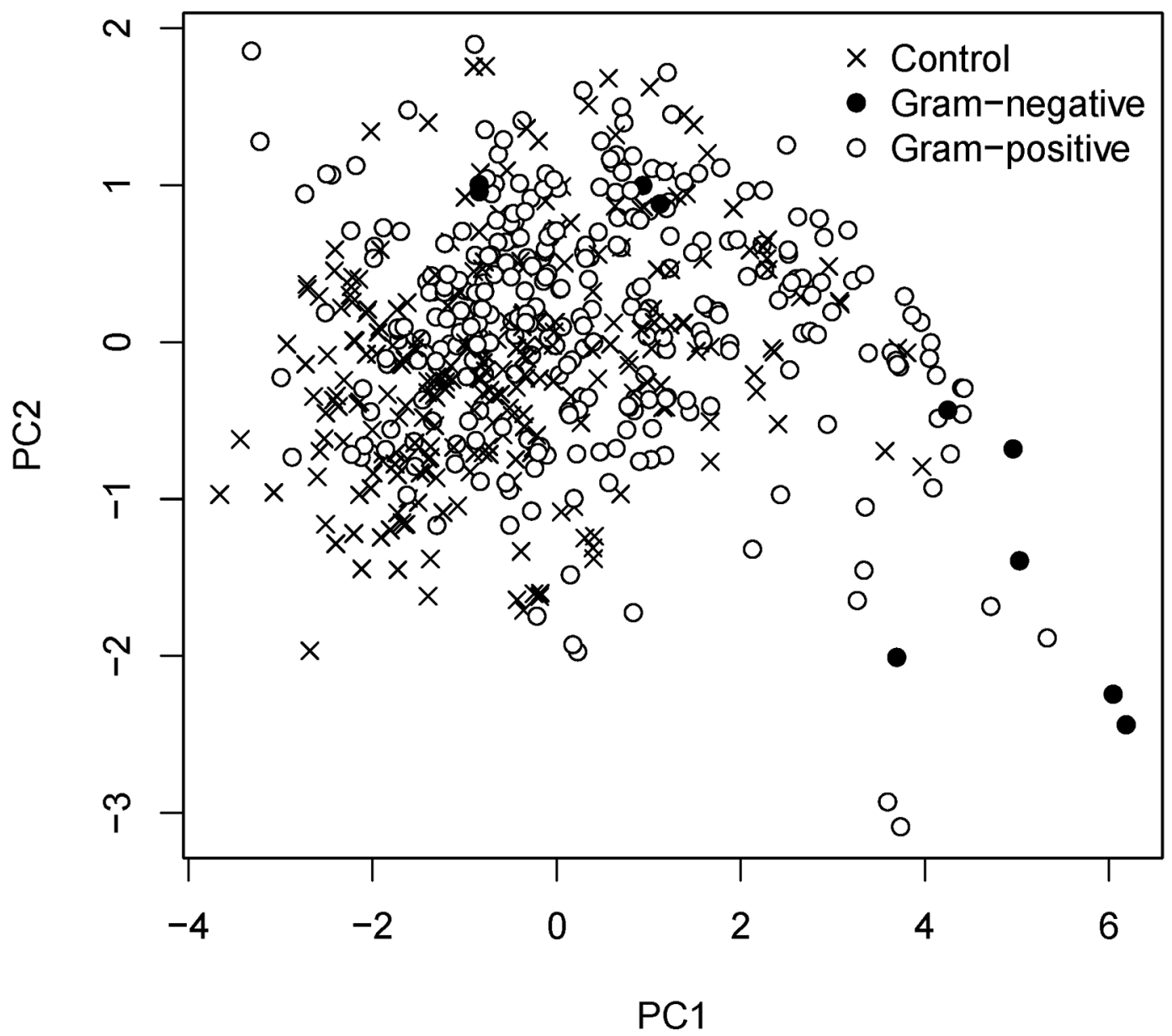

Figure 4. Plots of the first 2 principal component scores (PC1, PC2) for gram-positive $(\mathrm{n}=295)$ and gram-negative $(\mathrm{n}=10)$ IMI and control $(\mathrm{n}=329)$ quarters. Each infection type is indicated by the different point shapes.

pared with gram-positive IMI was also supported by the PCA where significantly greater PC1 scores (with approximately equal positive loadings of SCC, IgG,

Table 7. Model-based means ( \pm SE) of principal component scores (PC1, PC2) from a linear mixed model ${ }^{1}$ comparing IMI and control groups $^{2}$

\begin{tabular}{lrr}
\hline Culture $^{3}$ & PC1 score & \multicolumn{1}{c}{ PC2 score } \\
\hline Control $(\mathrm{n}=329)$ & $-0.01 \pm 0.35^{\mathrm{a}}$ & $0.01 \pm 0.15^{\mathrm{a}}$ \\
Gram-positive $(\mathrm{n}=295)$ & $0.29 \pm 0.36^{\mathrm{a}}$ & $-0.03 \pm 0.15^{\mathrm{a}}$ \\
Gram-negative $(\mathrm{n}=10)$ & $1.12 \pm 0.46^{\mathrm{b}}$ & $-0.65 \pm 0.21^{\mathrm{b}}$ \\
\hline
\end{tabular}

${ }_{\mathrm{a}, \mathrm{b}}$ Means within a column with different superscripts differ significantly $(P<0.05)$.

${ }^{1}$ Linear mixed models with the random effects for cow and cow-quarter.

${ }^{2}$ The principal component analysis was conducted on the 4 variables SCC, IgG, lactate dehydrogenase, and serum albumin responses.

${ }^{3}$ Culture: gram-negative $=$ IMI caused by gram-negative coliform bacteria; gram-positive = IMI caused by gram-positive bacteria; Control $=$ quarters without any bacterial growth.
$\mathrm{LDH}$, and SA) were found. The differences in SCC, $\mathrm{IgG}, \mathrm{LDH}$, and $\mathrm{SA}$ responses for gram-positive and gram-negative IMI might come from differential activation of the immune system by them (Wellnitz et al., 2011). The greatest correlation of LDH with SCC ( $\mathrm{r}=$ 0.80 ) indicates the concurrent stronger innate immune response and migration of the leucocytes into milk with greater damage of the mammary epithelial cells for LDH production (Wagner et al., 2009; Wellnitz et al., 2016; Hernández-Castellano et al., 2017). Additionally, the LDH control mean was $5.26 \times$ greater than the IMI groups, whereas the corresponding ratio for IgG was $1.63 \times$ and for SA was $2.48 \times$; these might be due to local LDH release from affected mammary epithelial cells, as IgG and SA originate exclusively from blood (Stelwagen et al., 1994; Wellnitz et al., 2016).

In mastitic quarters, greater SCC, IgG, LDH activity, and SA in BME samples compared with AME samples could be due to a protection mechanism against invad- 
Table 8. Model-based means ( \pm SE) of SCC, total IgG, lactate dehydrogenase (LDH), and serum albumin $(\mathrm{SA})$ in milk samples before and after ejection from linear mixed models ${ }^{1}$

\begin{tabular}{|c|c|c|c|}
\hline \multirow[b]{2}{*}{ Culture $^{2}$} & \multicolumn{2}{|c|}{ Time $^{3}$} & \multirow[b]{2}{*}{$P$-value } \\
\hline & $\mathrm{BME}$ & $\mathrm{AME}$ & \\
\hline \multicolumn{4}{|c|}{ Quarters with IMI and control $(\mathrm{n}=662)$} \\
\hline $\mathrm{SCC}\left(\log _{e}\right.$ cells $\left./ \mathrm{mL}\right)$ & $6.31 \pm 0.17$ & $5.89 \pm 0.17$ & $<0.001$ \\
\hline $\operatorname{IgG}(\mathrm{mg} / \mathrm{mL})$ & $0.96 \pm 0.08$ & $0.84 \pm 0.07$ & $<0.001$ \\
\hline $\mathrm{LDH}(\mathrm{U} / \mathrm{L})$ & $226 \pm 27$ & $159 \pm 19$ & $<0.001$ \\
\hline $\mathrm{SA}(\mathrm{mg} / \mathrm{mL})$ & $0.27 \pm 0.02$ & $0.24 \pm 0.02$ & $<0.001$ \\
\hline \multicolumn{4}{|c|}{ Quarters with IMI $(\mathrm{n}=328)$} \\
\hline $\mathrm{SCC}\left(\log _{e}\right.$ cells $\left./ \mathrm{mL}\right)$ & $6.77 \pm 0.19$ & $6.34 \pm 0.19$ & $<0.001$ \\
\hline $\operatorname{IgG}(\mathrm{mg} / \mathrm{mL})$ & $1.02 \pm 0.11$ & $0.91 \pm 0.10$ & $<0.001$ \\
\hline $\mathrm{LDH}(\mathrm{U} / \mathrm{L})$ & $313 \pm 54$ & $211 \pm 36$ & $<0.001$ \\
\hline $\mathrm{SA}(\mathrm{mg} / \mathrm{mL})$ & $0.33 \pm 0.03$ & $0.29 \pm 0.03$ & 0.010 \\
\hline \multicolumn{4}{|l|}{ Control $(\mathrm{n}=334)$} \\
\hline $\mathrm{SCC}\left(\log _{e}\right.$ cells $\left./ \mathrm{mL}\right)$ & $6.04 \pm 0.21$ & $5.61 \pm 0.21$ & $<0.001$ \\
\hline $\operatorname{IgG}(\mathrm{mg} / \mathrm{mL})$ & $0.91 \pm 0.08$ & $0.80 \pm 0.07$ & $<0.001$ \\
\hline $\mathrm{LDH}(\mathrm{U} / \mathrm{L})$ & $178 \pm 20$ & $130 \pm 14$ & $<0.001$ \\
\hline $\mathrm{SA}(\mathrm{mg} / \mathrm{mL})$ & $0.23 \pm 0.02$ & $0.21 \pm 0.02$ & 0.002 \\
\hline
\end{tabular}

${ }^{1}$ Linear mixed models to calculate predicted means of 4 outcome variables (SCC, IgG, lactate dehydrogenase activity, and serum albumin), with random effect estimates for each cow and cow-quarter.

${ }^{2}$ Culture: quarters with IMI: IMI caused by gram-positive or gram-negative bacteria; control = quarters without any bacterial growth.

${ }^{3} \mathrm{BME}=$ sampling times before ejection; $\mathrm{AME}=$ sampling times after ejection.

ing pathogens in the Furstenberg's rosette area of the teat (Nickerson and Pankey, 1983). Such differences in control (culture-negative healthy quarters with average SCC $<120,000$ cells $/ \mathrm{mL}$ ) might also be due to different pathways of transfer of SCC, IgG, LDH, and SA from blood into alveolar secretory tissue compared with teat tissue as reported for SCC previously (Sarikaya et al., 2005). Moreover, in mastitic and control quarters, the difference in SCC, IgG, LDH, and SA, particularly in the early- and mid-lactation period, might be due to the unequal distribution of the blood-milk barrier, which has also been shown for other parameters such as electrolytes, electrical conductivity, with generally more pronounced changes of milk composition in BME foremilk (Bruckmaier et al., 2004b). In the healthy quarters, the greater SCC responses in BME compared with AME samples was in contrast to previous findings where lower SCC was reported in the BME samples taken within $40 \mathrm{~s}$ of udder stimulation (Bruckmaier et al., 2004a). The reason for such variation could be that in this study the BME samples were taken within $\sim 60 \mathrm{~s}$ of udder touch and there were 8 quarters with prior dipping before BME sampling, leading to reduced concentration of SCC in AME samples (Lehmann et al., 2015). In mid-lactation period, the lower SCC and $\mathrm{LDH}$ (BME samples) responses in gram-negative IMI were due to a lower number of coliform cases (2 out of 12 ), as the majority of the coliform IMI (6 out of 12) were found in the early-lactation period (within 1 to 57 DIM). It should be noted that the number of gramnegative coliform observations was not very large $(\mathrm{n}=$
12) in this study, though there was sufficient statistical power to obtain statistical significance when comparing with the gram-positive IMI. Further studies should consider a herd approach to identify diversified and larger numbers of specific pathogens by a bulk-tank milk PCR test and investigation of the unequal distribution of the blood-milk barrier density in the entire mammary gland by measuring markers in fractionized milk samples collected in a noninvasive way.

\section{CONCLUSIONS}

Both LDH and SA could be used as replacement markers to indicate IgG transfer via the blood-milk barrier, and both are suitable to differentiate gram-positive and gram-negative IMI when combined with information generated from SCC. Further, SCC, IgG, LDH, and $\mathrm{SA}$ responses differ in vivo between gram-positive and gram-negative IMI. Foremilk BME is more sensitive to changes of blood-milk barrier integrity caused by IMI because milk ejection affects SCC, IgG, LDH, and SA in milk. Therefore, in AMS it would be advantageous for sensitive detection of IMI to perform the respective measurements in foremilk BME. Earlier differentiation of IMI type based on BME will be expected to minimize the antibiotic used for clinical mastitis.

\section{ACKNOWLEDGMENTS}

The authors thank Katrina Bosward from the University of Sydney for assistance in Coxiella burnetii 
antibody detection. We also thank Yolande Zbinden (laboratory staff of the University of Bern, Switzerland) for excellent technical assistance in the laboratory activities. The authors thank Ian Chapman and John Garrod (farm staff of the University of Sydney) and Kim McKean and Oliver Roberts (former farm managers of the University of Sydney) for their assistance in collecting the samples and data. This project was supported by FutureDairy (Camden, NSW, Australia), the Dairy Research Foundation of The University of Sydney (Australia) and partly by the University of Bern (Switzerland). The first author is a recipient of an Australian Endeavour PhD Scholarship. The authors have not stated any conflicts of interest.

\section{REFERENCES}

Bruckmaier, R. M., C. E. Ontsouka, and J. W. Blum. 2004a. Fractionized milk composition in dairy cows with subclinical mastitis. Vet. Med. (Praha) 49:283-290. https://doi.org/10.17221/5706 -VETMED.

Bruckmaier, R. M., D. Weiss, M. Wiedemann, S. Schmitz, and G. Wendl. 2004b. Changes of physicochemical indicators during mastitis and the effects of milk ejection on their sensitivity. J. Dairy Res. 71:316-321. https://doi.org/10.1017/S0022029904000366.

Bruckmaier, R. M., and O. Wellnitz. 2017. Triennial Lactation Symposium/BOLFA: Pathogen-specific immune response and changes in the blood-milk barrier of the bovine mammary gland. J. Anim. Sci. 95:5720-5728. https://doi.org/10.2527/jas2017.1845.

Burton, J. L., and R. J. Erskine. 2003. Immunity and mastitis. Some new ideas for an old disease. Vet. Clin. North Am. Food Anim. Pract. 19:1-45. https://doi.org/10.1016/S0749-0720(02)00073-7.

Butler, D. G., B. R. Cullis, A. R. Gilmour, B. G. Gogel, and R. Thompson. 2017. ASReml-R Reference Manual Version 4. VSN International Ltd.

Cheng, J., J. Zhang, J. Yang, B. Yi, G. Liu, M. Zhou, J. P. Kastelic, B. Han, and J. Gao. 2021. Klebsiella pneumoniae infection causes mitochondrial damage and dysfunction in bovine mammary epithelial cells. Vet. Res. 52:17. https://doi.org/10.1186/s13567-021 $-00898-\mathrm{x}$.

Dzidic, A., J. Macuhova, and R. M. Bruckmaier. 2004. Effects of cleaning duration and water temperature on oxytocin release and milk removal in an automatic milking system. J. Dairy Sci. 87:41634169. https://doi.org/10.3168/jds.S0022-0302(04)73559-6.

Halasa, T., K. Huijps, O. Østerås, and H. Hogeveen. 2007. Economic effects of bovine mastitis and mastitis management: A review. Vet. Q. 29:18-31. https://doi.org/10.1080/01652176.2007.9695224.

Hanley, J. A., and B. J. McNeil. 1982. The meaning and use of the area under a receiver operating characteristic (ROC) curve. Radiology 143:29-36. https://doi.org/10.1148/radiology.143.1.7063747.

Hernández-Castellano, L. E., S. K. Wall, R. Stephan, S. Corti, and R. Bruckmaier. 2017. Milk somatic cell count, lactate dehydrogenase activity, and immunoglobulin G 2 concentration associated with mastitis caused by different pathogens: A field study. Schweiz. Arch. Tierheilkd. 159:283-290. https://doi.org/10.17236/sat00115.

Hogeveen, H., C. Kamphuis, W. Steeneveld, and H. Mollenhorst. 2010. Sensors and clinical mastitis-the quest for the perfect alert. Sensors (Basel) 10:7991-8009. https://doi.org/10.3390/s100907991.

Huijps, K., T. J. Lam, and H. Hogeveen. 2008. Costs of mastitis: facts and perception. J. Dairy Res. 75:113-120. https://doi.org/10 .1017/S0022029907002932.

Khatun, M., R. M. Bruckmaier, P. C. Thomson, J. House, and S. C. García. 2019. Suitability of somatic cell count, electrical conductivity, and lactate dehydrogenase activity in foremilk before versus after alveolar milk ejection for mastitis detection. J. Dairy Sci. 102:9200-9212. https://doi.org/10.3168/jds.2018-15752.

Lehmann, M., S. K. Wall, O. Wellnitz, and R. M. Bruckmaier. 2015. Changes in milk L-lactate, lactate dehydrogenase, serum albumin, and IgG during milk ejection and their association with somatic cell count. J. Dairy Res. 82:129-134. https://doi.org/10.1017/ S002202991400065X

Lehmann, M., O. Wellnitz, and R. M. Bruckmaier. 2013. Concomitant lipopolysaccharide-induced transfer of blood-derived components including immunoglobulins into milk. J. Dairy Sci. 96:889-896. https://doi.org/10.3168/jds.2012-5410.

Mačuhová, J., V. Tančin, and R. M. Bruckmaier. 2003. Oxytocin release, milk ejection and milk removal in a multi-box automatic milking system. Livest. Prod. Sci. 81:139-147. https://doi.org/10 .1016/S0301-6226(02)00304-4.

Milner, P., K. L. Page, and J. E. Hillerton. 1997. The effects of early antibiotic treatment following diagnosis of mastitis detected by a change in the electrical conductivity of milk. J. Dairy Sci. 80:859863. https://doi.org/10.3168/jds.S0022-0302(97)76008-9.

Nickerson, S. C., and J. W. Pankey. 1983. Cytologic observations of the bovine teat end. Am. J. Vet. Res. 44:1433-1441.

Pyörälä, S. 2003. Indicators of inflammation in the diagnosis of mastitis. Vet. Res. 34:565-578. https://doi.org/10.1051/vetres:2003026.

Robin, X., N. Turck, A. Hainard, N. Tiberti, F. Lisacek, J. Sanchez, and M. Mueller. 2011. pROC: An open-source package for R and $\mathrm{S}+$ to analyze and compare ROC curves. BMC Bioinformatics 12:77.

Ruopp, M. D., N. J. Perkins, B. W. Whitcomb, and E. F. Schisterman. 2008. Youden Index and optimal cut-point estimated from observations affected by a lower limit of detection. Biom. J. 50:419-430. https://doi.org/10.1002/bimj.200710415.

Sarikaya, H., C. Werner-Misof, M. Atzkern, and R. M. Bruckmaier. 2005. Distribution of leucocyte populations, and milk composition, in milk fractions of healthy quarters in dairy cows. J. Dairy Res. 72:486-492. https://doi.org/10.1017/S0022029905001317.

Schmitz, S., M. W. Pfaffl, H. H. D. Meyer, and R. M. Bruckmaier. 2004. Short-term changes of mRNA expression of various inflammatory factors and milk proteins in mammary tissue during LPSinduced mastitis. Domest. Anim. Endocrinol. 26:111-126. https:// doi.org/10.1016/j.domaniend.2003.09.003.

Shamay, A., R. Homans, Y. Fuerman, I. Levin, H. Barash, N. Silanikove, and S. J. Mabjeesh. 2005. Expression of albumin in nonhepatic tissues and its synthesis by the bovine mammary gland. J. Dairy Sci. 88:569-576. https://doi.org/10.3168/jds.S0022-0302(05)72719 -3 .

Steeneveld, W., J. C. M. Vernooij, and H. Hogeveen. 2015. Effect of sensor systems for cow management on milk production, somatic cell count, and reproduction. J. Dairy Sci. 98:3896-3905. https:// doi.org/10.3168/jds.2014-9101.

Stelwagen, K., C. G. Prosser, S. R. Davis, V. C. Farr, I. Politis, J. H. White, and B. Zavizion. 1994. Effect of milking frequency and somatotropin on the activity of plasminogen activator, plasminogen, and plasmin in bovine milk. J. Dairy Sci. 77:3577-3583. https:// doi.org/10.3168/jds.S0022-0302(94)77301-X.

Swets, J. A. 1988. Measuring the accuracy of diagnostic systems. Science 240:1285-1293. https://doi.org/10.1126/science.3287615.

Verbyla, A. P., B. R. Cullis, M. G. Kenward, and S. J. Welham. 1999. The analysis of designed experiments and longitudinal data by using smoothing splines. Appl. Stat. 48:269-311. https://doi.org/10 $.1111 / 1467-9876.00154$.

Wagner, S. A., D. E. Jones, and M. D. Apley. 2009. Effect of endotoxic mastitis on epithelial cell numbers in the milk of dairy cows. Am. J. Vet. Res. 70:796-799. https://doi.org/10.2460/ajvr.70.6.796.

Wall, S. K., J. J. Gross, E. C. Kessler, K. Villez, and R. M. Bruckmaier. 2015. Blood-derived proteins in milk at start of lactation: Indicators of active or passive transfer. J. Dairy Sci. 98:7748-7756. https://doi.org/10.3168/jds.2015-9440.

Wall, S. K., O. Wellnitz, L. E. Hernández-Castellano, A. Ahmadpour, and R. M. Bruckmaier. 2016. Supraphysiological oxytocin increases the transfer of immunoglobulins and other blood components 
to milk during lipopolysaccharide- and lipoteichoic acid-induced mastitis in dairy cows. J. Dairy Sci. 99:9165-9173. https://doi .org/10.3168/jds.2016-11548.

Wellnitz, O., E. T. Arnold, and R. M. Bruckmaier. 2011. Lipopolysaccharide and lipoteichoic acid induce different immune responses in the bovine mammary gland. J. Dairy Sci. 94:5405-5412. https:// doi.org/10.3168/jds.2010-3931.

Wellnitz, O., E. T. Arnold, M. Lehmann, and R. M. Bruckmaier. 2013. Short communication: Differential immunoglobulin transfer during mastitis challenge by pathogen-specific components. J. Dairy Sci. 96:1681-1684. https://doi.org/10.3168/jds.2012-6150.

Wellnitz, O., and R. M. Bruckmaier. 2012. The innate immune response of the bovine mammary gland to bacterial infection. Vet. J. 192:148-152. https://doi.org/10.1016/j.tvjl.2011.09.013.
Wellnitz, O., C. Zbinden, X. Huang, and R. M. Bruckmaier. 2016. Short communication: Differential loss of bovine mammary epithelial barrier integrity in response to lipopolysaccharide and lipoteichoic acid. J. Dairy Sci. 99:4851-4856. https://doi.org/10.3168/ jds.2016-10927.

\section{ORCIDS}

M. Khatun $\odot$ https://orcid.org/0000-0002-8992-188X

P. C. Thomson $\odot$ https://orcid.org/0000-0003-4428-444X

S. C. García @ic https://orcid.org/0000-0002-2742-0262

R. M. Bruckmaier ㅇ https://orcid.org/0000-0002-9374-5890 